\title{
Integrin-Dependent Akt1 Activation Regulates PGC-1 Expression and Fatty Acid Oxidation
}

\author{
Craig C. Beeson $^{\mathrm{b}}$ Gyda C. Beeson ${ }^{\mathrm{b}}$ Haley Buffa Juanita Eldridge ${ }^{\mathrm{a}}$ \\ Aiguo Zhang ${ }^{d}$ Arun Seth $^{d}$ Marina Demchevac John N. Vournakis ${ }^{c}$ \\ Robin C. Muise-Helmericks ${ }^{a}$ \\ ${ }^{a}$ Department of Regenerative Medicine and Cell Biology and ${ }^{b}$ Department of Pharmaceutical and Biomedical \\ Sciences, Medical University of South Carolina, Charleston, S.C., and 'Marine Polymer Technologies, Inc., \\ Danvers, Mass., USA; d Sunnybrook Research Institute and Department of Laboratory Medicine and Pathobiology, \\ University of Toronto, Toronto, Ont., Canada
}

\section{Key Words}

Angiogenesis - Oxygen consumption - Fatty acid oxidation • Integrin $\cdot$ Akt1 gene $\cdot$ Peroxisome proliferator-activated receptor $\gamma$ coactivator-1

\begin{abstract}
Background: Poly-N-acetyl glucosamine nanofibers derived from a marine diatom have been used to increase cutaneous wound healing. These nanofibers exert their activity by specifically activating integrins, which makes them a useful tool for dissecting integrin-mediated pathways. We have shown that short-fiber poly-N-acetyl glucosamine nanofiber (sNAG) treatment of endothelial cells results in increased cell motility and metabolic rate in the absence of increased cell proliferation. Results: Using a Seahorse Bioanalyzer to measure oxygen consumption in real time, we show that sNAG treatment increases oxygen consumption rates, correlated with an integrin-dependent activation of Akt1. Akt1 activation leads to an increase in the expression of the transcriptional coactivator, peroxisome proliferator-activated receptor $\gamma \mathrm{co}-$ activator-1 $\alpha$ (PGC-1 $\alpha)$. This is not due to increased mitochondrial biogenesis, but is associated with an increase in the ex-
\end{abstract}

pression of pyruvate dehydrogenase kinase 4 (PDK4), suggesting regulation of fatty acid oxidation. Blockade of fatty acid oxidation with etomoxir, an O-carnitine palmitoyltransferase-1 inhibitor, blocks the sNAG-dependent increased oxygen consumption. ${ }^{3} \mathrm{H}$-palmitate uptake experiments indicate a PDK4-dependent increase in fatty acid oxidation, which is required for nanofiber-induced cell motility. Conclusions: Our findings imply a linear pathway whereby an integrin-dependent activation of Akt 1 leads to increased PGC- $1 \alpha$ and PDK4 expression resulting in increased energy production by fatty acid oxidation.

Copyright $\odot 2012$ S. Karger AG, Basel

\section{Introduction}

Increased angiogenesis is a hallmark of cutaneous wound healing and is necessary to support new tissue formation [1]. VEGF production is strongly upregulated in wound healing via secretion by activated macrophage and keratinocytes working together to stimulate new capillary production within the wounded area. Impairment of new vessel formation results in decreased wound

\section{KARGER}

Fax +4161306 1234 E-Mail karger@karger.ch www.karger.com

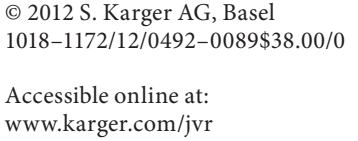

Dr. Robin C. Muise-Helmericks

Medical University of South Carolina

173 Ashley Ave, BSB654

Charleston, SC 29425 (USA)

Tel. +1 843792 4760, E-Mail musehelm@musc.edu 
healing abilities [2-4]. Concentrated efforts have been made to increase vascularization for tissue regeneration and the repair of chronic, nonhealing ischemic wounds [5]. New therapies using recombinant growth factors or vascular progenitor cells to foster the formation of new blood vessels have been proposed, some of which are currently in phase II/III trials [6, 7].

The isolation and formulation of highly pure and homogenous poly-N-acetyl glucosamine nanofibers i.e. short-fiber poly- $\mathrm{N}$-acetyl glucosamine nanofibers (sNAGs) from a marine diatom are currently used as a hemostatic agent in the clinical arena $[8,9]$, fully activating platelets via an integrin-dependent mechanism [10]. Importantly, platelet activation by sNAGs is mediated by their association with integrin $\beta 3$ and activation of integrin-mediated signaling [11]. Indeed, these nanofibers have been shown to specifically bind integrins in pulldown assays [11]. Recent findings show that the treatment of cutaneous wounds with sNAG-derived membranes results in increased kinetics of wound healing that can be attributed, in part, to a marked increase in angiogenesis $[12,13]$. We have shown that sNAG treatment stimulates wound integrin-dependent signaling pathways that result in increased endothelial cell motility $[12,14]$. Together these findings suggest that sNAGs promote wound healing and angiogenesis via the stimulation of outsidein integrin signal transduction.

Angiogenesis is a highly anabolic process, requiring higher bioenergetics and ATP input than quiescent tissues. Indeed, stimulation of endothelial cells with sNAGs results in increased metabolic activity in the absence of cell proliferation, suggesting that sNAG stimulation of integrin-mediated signal transduction increases mitochondrial function and energy production. Mitochondrial oxidative metabolism and respiration capacity is controlled by a coordinated transcriptional program induced in response to high energy demands such as exercise, fasting and exposure to the cold. A key player in this transcriptional program is the peroxisome proliferator-activated receptor $\gamma$ coactivator-1 (PGC-1). PGC-1 $\alpha$ (PPAR $\gamma$ coactivator $\alpha$ ) is a transcriptional coactivator responsible for the transcriptional control of genes involved in mitochondrial biogenesis and oxidative metabolism, acting both upstream and in consort with nuclear respiratory factors 1 and 2 (NRF-1 and NRF-2) [15-17]. Overexpression of PGC-1 $\alpha$ results in the increased expression of both mitochondrial and nuclear-encoded mitochondrial genes $[18,19]$. PGC-1 $\alpha$ also regulates those genes involved in fatty acid catabolism through the coactivation of the PPARs and ERR $\alpha$. PGC- $1 \alpha$ has specific functions in dif- ferent tissues. For example, in the liver, it regulates gluconeogenesis via the induction of phosphoenol pyruvate carboxykinase and glucose-6-phosphatase, and in skeletal muscle, it promotes glucose uptake. PGC-1 $\alpha$ is therefore thought to be a central regulator of bioenergetic functions.

Several signaling pathways have been implicated in the regulation of PGC-1 $\alpha$ activity [20]. In response to contractile activity in muscle, calcium-mediated signal transduction leads to increased mitochondrial biogenesis through a CaMK-dependent increase in PGC-1 $\alpha$ expression $[21,22]$. It is well documented that cAMP-dependent/responsive element-binding (CREB) protein activation resulting from cold or fasting causes an upregulation of PGC-1 $\alpha$ expression. In addition to changes in expression, PGC- $1 \alpha$ activity can also be controlled by phosphorylation via p38 MAP kinase activation [23] and by acetylation [24]. We have shown that Akt3 controls the nuclear localization of PGC- $1 \alpha$ and thus its downstream regulation of genes controlling mitochondrial biogenesis [25].

Here, we show that sNAG stimulation of primary endothelial cells results in increased oxygen consumption in primary endothelial cells that can be attributed to an integrin-dependent upregulation of PGC-1 $\alpha$ by a pathway that is Akt1-dependent. The increased expression of PGC- $1 \alpha$ does not result in an increase in mitochondrial biogenesis. Instead, integrin activation of the Akt1/PGC1 pathway results in an increase in fatty acid oxidation via the regulation of pyruvate dehydrogenase kinase 4 (PDK4). Our findings suggest a linear pathway whereby an integrin-dependent activation of Akt1 via sNAG stimulation leads to increased PGC- $1 \alpha$ and PDK4 expression, resulting in an increase in energy production by increased fatty acid oxidation which is required for endothelial cell motility.

\section{Materials and Methods}

Tissue Culture, Growth Factors and Drugs

Pooled, multiple-donor human umbilical vein endothelial cells (HUVEC; Lonza) were maintained at $37^{\circ} \mathrm{C}$ with $5 \% \mathrm{CO}_{2}$ in endothelial basal medium 2 (Lonza) supplemented with EGM-2 SingleQuots as described by Cambrex procedures. Serum starvation was performed at $80-90 \%$ confluency in RPMI1640 supplemented with $0.1 \%$ fetal calf serum (Valley Biomedical) for $24 \mathrm{~h}$, followed by stimulation with highly purified pGlcNAc nanofibers in sterile water (Marine Polymer Technologies, Inc., Danvers, Mass., USA) with the amounts and times indicated in the text. For wortmannin $(100 \mathrm{nM})$ or PD098059 $(50 \mu \mathrm{M})$ treatment, serumstarved cells were pretreated for $30 \mathrm{~min}$ prior to pGlcNAc nano- 
fiber (i.e. sNAG) stimulation. For integrin blocking experiments, serum-starved cells were pretreated with antibody for $30 \mathrm{~min}$ prior to stimulation with pGlcNAc nanofibers. The pGlcNAc diatom-derived nanofibers used in this study are short biodegradable fibers derived from a native, longer form, and have an average length of 4-7 $\mu \mathrm{m}$ and a polymer molecular weight of approximately 60,000 Da.

\section{Lentiviral Infection}

Mission shRNA lentiviral constructs directed against Akt1 were purchased from Sigma/Aldrich. A scrambled pLKO.1 shRNA vector was purchased from Addgene. Lentiviruses were propagated in 293T cells, maintained in DMEM supplemented as above. Lentiviral production was performed using psPAX2 and pMD2.G packaging vectors purchased from Addgene using their protocol for producing lentiviral particles. For the infection of target cells, $7.5 \times 10^{5}$ cells were plated on $100-\mathrm{mm}^{2}$ plates and allowed to incubate overnight. The next day, cells were infected using a final concentration of $1 \mu \mathrm{g} / \mathrm{ml}$ polybrene and either scrambled control or Akt1 shRNA lentiviruses. All infections were monitored for appropriate knockdown by RT-PCR.

\section{Measurements of $\mathrm{O}_{2}$ Consumption}

A Seahorse Bioscience XF24 instrument was used to measure the rate of change of dissolved $\mathrm{O}_{2}$ and $\mathrm{pH}$ in medium immediately surrounding HUVEC cultured in 24-well plates. Measurements were performed using a cartridge where 24 optical fluorescent $\mathrm{O}_{2}$ and $\mathrm{pH}$ sensors are configured as individual well 'plungers'. For measurements of rates, the plungers gently descended into the wells, forming a transient chamber that entraps the cells in approximately $7 \mu$ l volume. The rates of $\mathrm{O}_{2}$ concentration and extracellular acidification were obtained from the slopes of concentration changes versus time measured during serial 90 -second plunge periods that were followed by 60 -second mix and 60 -second wait periods. Various metabolic inhibitors were added via automatic injectors followed by periods of $60 \mathrm{~s}$ of mixing and $60 \mathrm{~s}$ of waiting.

\section{${ }^{3}$ H-Palmitate Uptake Assays}

HUVEC were plated in 24-well plates, serum starved or treated with sNAG $(50 \mu \mathrm{g} / \mathrm{ml})$ overnight. Media were replaced with media plus $0.1 \%$ FFA-free BSA with $5 \mu \mathrm{Ci}{ }^{3} \mathrm{H}-9,10$-palmitate $/ 1 \mu \mathrm{l}$ and $0.15 \mathrm{~mm}$ palmitate and allowed to incubate for $60 \mathrm{~min}$. Seventy-five microliters from each well were placed into a $0.5-\mathrm{ml} \mathrm{mi}$ crocentrifuge tube contained within a scintillation vial which was loaded with $75 \mu$ l of deionized water. The scintillation vials were tightly capped and incubated at $37^{\circ} \mathrm{C}$ overnight to equilibrate the ${ }^{3} \mathrm{HOH}$ in the media aliquot with the water in the microfuge tube. After equilibration, the microfuge tubes were removed and the cpm in the remaining $75 \mu \mathrm{l}$ in the scintillation vial were counted using a Packard Tri-Carb 2900TR scintillation vial. Each assay was performed in quadruplicate.

\section{Proliferation Assays}

For cellular proliferation/viability assessment, two different assays were used; trypan blue exclusion by direct cell counts using a hemacytometer and by a MTT (3-(4,5-dimethylthiazol-2yl)-2,5diphenyltetrazolium bromide) assay in procedures described by the manufacturer (Promega).

Integrin Stimulation of Fatty Acid Metabolism

\section{Transfection}

HUVEC were transfected using the Amaxa nucleofector system in procedures described by the manufacturer, obtaining transfection efficiencies of up to $80 \%$. All transfections were monitored by the expression of green fluorescent protein (GFP) using a GFP expression vector pFP-C1 (Clontech) or a GFP-directed RNAi (Amaxa). RNAi directed against Akt3, integrin-linked kinase 1 (ILK1) and PDK4 and scrambled control were purchased from Santa Cruz Biotechnologies and used at empirically determined amounts.

\section{Cell Migration Assays}

For modified transwell assays, transfected or untransfected HUVEC were plated onto $8 \mu \mathrm{m}$-pore size invasion chambers precoated with fibronectin at $20 \mu \mathrm{g} / \mu \mathrm{l}$ (Sigma), $5 \times 10^{4}$ cells per chamber in $500 \mu \mathrm{l}$ of serum starvation media and $500 \mu \mathrm{l}$ of starvation media were added to the well. sNAGs $(50 \mu \mathrm{g} / \mathrm{ml})$ were added to the upper chamber. Cells were incubated for $12 \mathrm{~h}$ at $37^{\circ} \mathrm{C}$ in the presence of $5 \% \mathrm{CO}_{2}$. Cells that did not migrate were removed by wiping the top of each membrane with a cotton swab. The migrated cells were fixed in methanol for $10 \mathrm{~min}$ and stained with $0.1 \mu \mathrm{g} / \mathrm{ml}$ ethiduim bromide in PBS. Migrated cells were counted using a Leica fluorescent microscope. Each assay was performed at least 3 times, each time in triplicate, and at least 6 fields per transwell were counted.

\section{Antibodies, Western Blot and Kinase Analyses}

The antibodies used for Western blot analysis were as follows: anti-p85 subunit of PI3K and Oxphos antibody (Upstate Biotechnology), phosphospecific Akt antibody (Cell Signaling Technologies). For kinase assays, a nonradioactive Akt kinase kit from Cell Signaling Technologies was used. Briefly, Akt1 was immunoprecipitated from serum-starved or sNAG-treated HUVEC using an Aktl antibody (Santa Cruz) and incubated with a mixture containing the substrate, glycogen synthase kinase-3 (GSK). After incubation, Western blot analyses were performed using an antibody directed against phosphorylated GSK (p-GSK). Anti-ILK1 antibodies were purchased from Millipore and anti-PGC-1 antibodies were obtained from Calbiochem. For integrin blocking experiments, cells were pretreated for $30 \mathrm{~min}$ prior to sNAG stimulation using blocking antibodies directed against integrin $\alpha 5 \beta 1$ and $\beta 1$ which were purchased from Chemicon.

\section{Reverse Transcription Polymerase Chain Reaction}

For semi-quantitative RT-PCR, RNA was extracted with RNAsol (Teltest, Inc.) following manufacturer's instructions. cDNA was synthesized from $2 \mu \mathrm{g}$ total RNA with a Superscript First Strand Synthesis kit (Invitrogen) using Oligo (dT), following the manufacturer's instructions. PCR reactions contained equal amounts of cDNA and $1.25 \mu \mathrm{M}$ of the appropriate primer pair (Sigma-Proligo, St. Louis, Mo., USA). All primer sequences used in these analyses were as follows: Akt1 forward 5' GAGGCCGTCAGCCACAGTCTG $3^{\prime}$ and reverse 5' ATGAGCGACGTGGCTATTGTG 3'; PGC- $1 \alpha$ forward 5' GCAGAGAGGGAACTTTGCAC 3' and reverse 5' AGGGCTCAACTAATCGCTCA 3'; CoxII forward $5^{\prime}$ TCCATGATCACGCCCTCATA $3^{\prime}$ and reverse 5' TAAAGGATGCGTAGGGATGG 3'; HPRT forward 5' CTTGCTCGAGATGTGATGA and reverse 5' GTCTGCATTGTTTTGCCAGTG 3'; S26 forward 5' CTCCGGTCCGTGCCTCCAAG 3' reverse 5' CAGAGAATAGCCTGTCTTCAG 3'; PDK1 forward 5' 


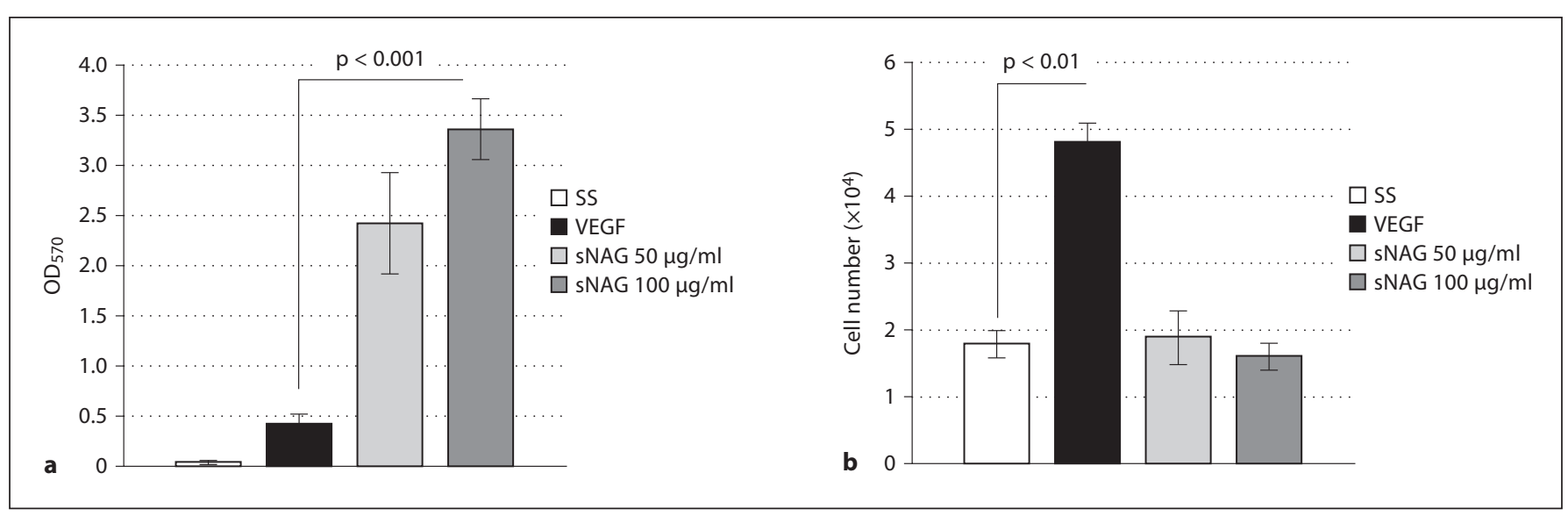

Fig. 1. sNAG treatment induces metabolic activity in the absence of cell proliferation. a Serum-starved HUVEC (SS) were stimulated with sNAGs at two different concentrations or with VEGF $(20 \mathrm{ng} / \mathrm{ml})$ and evaluated with an MTT assay. b Cells were treated (as in a) and tested for changes in number by direct cell counts $48 \mathrm{~h}$ after treatment. Each assay was performed 3 times, each time in triplicate.

CACGCTGGGTAATGAGGATT 3' and reverse 5' ACTGCATCTGTCCCGTAACC 3'; PDK2 forward 5' AGCTGGTGCAGAGCTGGTAT $3^{\prime}$ and reverse 5' CTGAGGTAGAAGCGGTCCAG 3'; PDK3 forward 5' GCTCTTGTGCCCTCGTACTC 3' and reverse 5' CTAGGTGGAGGTTTGGGACA 3'; PDK4 forward 5' CCTTTGGCTGGTTTTGGTTA 3' and reverse 5' CCTG CTTGGGATACACCAGT $3{ }^{\prime}$. Cycling conditions were: $94^{\circ} \mathrm{C}$ for $5 \mathrm{~min}, 30-35$ cycles of $94^{\circ} \mathrm{C}$ for $1 \mathrm{~min}, 55-65^{\circ} \mathrm{C}$ (based on primer $\mathrm{T}_{\mathrm{m}}$ ) for $1 \mathrm{~min}, 72^{\circ} \mathrm{C}$ for $1 \mathrm{~min}, 72^{\circ} \mathrm{C}$ for $7 \mathrm{~min}$ and then cooled to $4^{\circ} \mathrm{C}$. The cycle number was empirically determined to be within the linear range of the assay for each primer pair used. All semiquantitative RT-PCR was performed in tandem with hypoxanthine-guanine phosphoribosyltransferase (HPRT) or the ribosomal protein subunit S26 primers as internal controls. Products were run on 1-1.5\% (based on product size) agarose gels and visualized on a BioRad Molecular Imaging System (Hercules, Calif., USA).

Real-time PCR was performed using a Brilliant SYBR green QPCR kit in combination with an Mx3000P Real-Time PCR System, both purchased from Stratagene. Internal control primers that detect S26 were used. Real-time PCR was performed at least 3 times, each time in triplicate.

\section{Microarray Analyses}

To identify genes that are regulated by sNAG treatment, gene expression profiles were generated comparing untreated HUVEC and those treated with $10 \mu \mathrm{g} / \mathrm{ml}$ sNAGs for $5 \mathrm{~h}$. Microarray data was generated using $28 \mathrm{~K}$ whole genome microarrays and a statistical comparison was performed using the GeneSpring GX 7.3.1 software suite. Confirmation of the microarray data was performed using an ABI Prism 7000 for real-time PCR.

\section{Statistical Analyses}

Each quantitative experiment was performed at least 3 times, each time in triplicate. All statistical analyses were performed using Microsoft Excel to calculate means, standard deviations, and Student $t$ tests.

\section{Results}

\section{Integrin Stimulation by sNAG Treatment Increases Metabolic Rate}

Our previously published findings show that sNAG treatment of HUVEC results in integrin stimulation of Ets1 expression and that Ets1 is required for motility. To test whether the nanofibers affected HUVEC proliferation, sNAG-treated HUVEC were subjected to MTT assays. Figure la shows that treating of serum-starved HUVEC overnight with 2 concentrations of sNAGs resulted in a 3.5-fold increase in the conversion of MTT to formazan, as measured by the absorbance at $570 \mathrm{~nm}$. VEGF also caused an increase in absorbance but to a much lesser extent. Figure $1 \mathrm{~b}$ shows that the pGlcNAc-dependent increase in absorbance was not correlated with increased cell numbers, as measured by direct cell counts after $48 \mathrm{~h}$ of treatment, compared to VEGF stimulation. Given that MTT conversion to formazan is largely controlled by mitochondrial reductases, this assay is a measurement of metabolic activity. To confirm that the nanofibers were indeed affecting metabolic rate, their effect on $\mathrm{O}_{2}$ consumption, in real time, was measured using a Seahorse Biosciences respirometry instrument. The graph in figure 2a shows that $\mathrm{O}_{2}$ consumption rates increased upon the addition of sNAGs and increased markedly upon the addition of carbonyl cyanide-p-trifluoromethoxyphenylhydrazone (FCCP), a mitochondrial uncoupler used as a positive control. The average uncoupled $\mathrm{O}_{2}$ consumption rates are shown in the graph in figure $2 \mathrm{~b}$. 


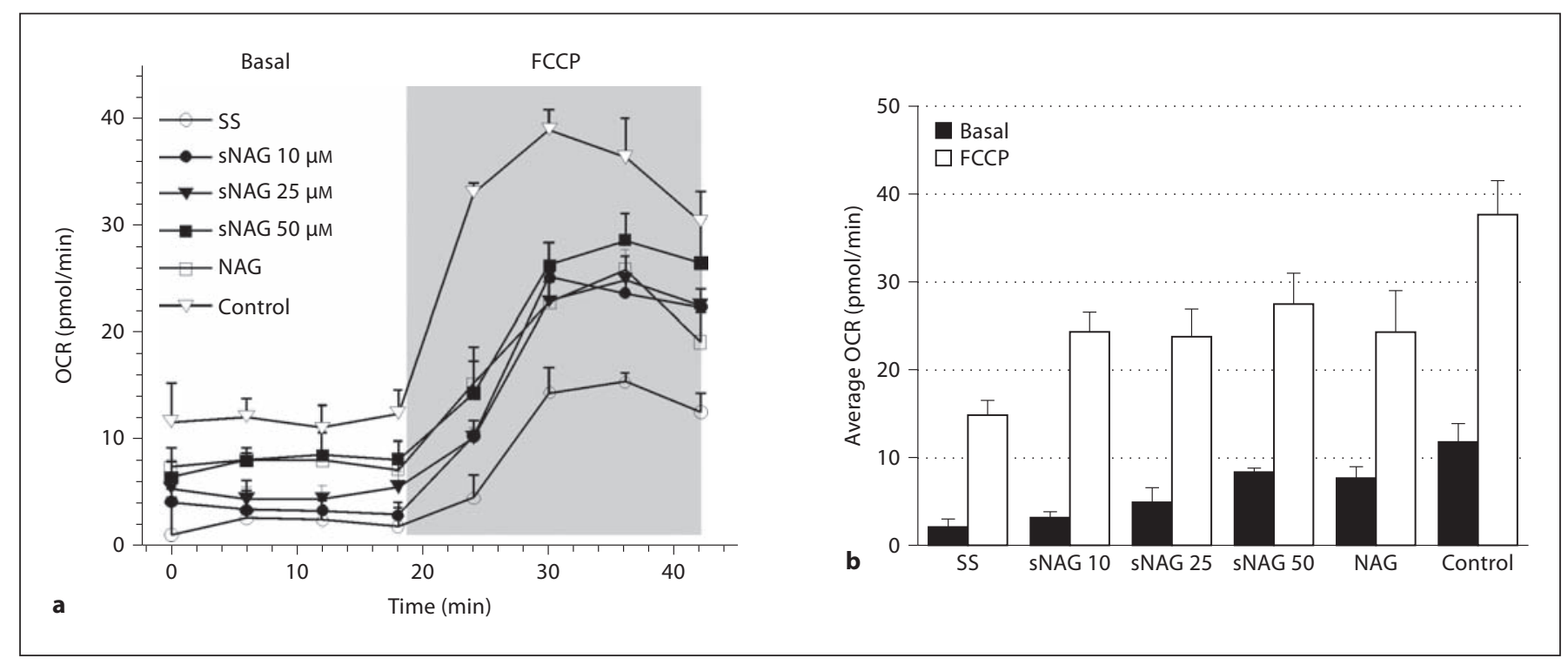

Fig. 2. sNAG treatment stimulates $\mathrm{O}_{2}$ consumption. Serumstarved HUVEC were treated with sNAGs or the full-length nanofibers (NAG) overnight at the concentrations indicated prior to assessment using a Seahorse Biosciences XF 24 analyzer. Ten percent fetal calf serum was used as a positive control

These results suggest that sNAG treatment increases the metabolic rate and mitochondrial capacity of primary endothelial cells.

\section{pGlcNAc Nanofibers Stimulate PGC-1 $\alpha$ Expression via an Akt1-Dependent Pathway}

Using gene array analyses, we assessed global changes in gene expression in response to $\mathrm{sNAG}$ treatment of HUVEC and could hereby demonstrate a marked increase in PGC- $1 \alpha$ expression within $5 \mathrm{~h}$ of treatment. The PGC-1 $\alpha$ transcription factor is considered a master regulator of mitochondrial function. Quantitative PCR confirmation of the microarray analysis is shown in figure 3a. This increase in mRNA expression is also correlated to an increase in PGC- $1 \alpha$ protein expression (fig. $3 b$ ). Pharmacological inhibitors were used to determine the signaling pathway that controls PGC- $1 \alpha$ expression. HUVEC were pretreated either with PD098059 to inhibit the MEK1/ERK pathway or with wortmannin to inhibit the PI3-kinase/Akt pathway. Figure $3 \mathrm{c}$ and the quantitation in figure $3 \mathrm{~d}$ show that sNAG treatment causes an increase in the expression of PGC- $1 \alpha$ transcript that is inhibited by blockade of the PI3K/Akt pathway.

To determine whether Akt was stimulated by sNAG treatment, HUVEC were treated with sNAGs and as-
(Control). a Oxygen consumption rates (OCR); the shadowed region indicates the time at which FCCP, a mitochondrial uncoupling agent, was added. b Graph depicts average oxygen consumption rates (as in a). These assays were repeated at least 3 times. sessed for changes in the phosphorylation of Akt. The result (fig. 4a) was an increase in Akt phosphorylation. To determine whether sNAG treatment also resulted in a stimulation of Akt1 kinase activity, Akt1 was immunoprecipitated and tested for its ability to phosphorylate the exogenous substrate GSK (fig. $4 \mathrm{~b}$ ). Increased p-GSK demonstrated that sNAG treatment increased Akt1 activity.

To confirm a role for Aktl in the increased expression of PGC-1 $\alpha$, the knockdown of Akt1 was achieved using lentiviruses expressing Akt1 shRNA. The result was a reduction in the expression of PGC-1 $\alpha$ (fig. 4c). The effect on PGC-1 $\alpha$ is specific to Akt1 as the knockdown of Akt3 did not cause a similar effect (fig. $4 \mathrm{~d}$ ). These results suggest that the integrin activation of Akt1 results in increased PGC- $1 \alpha$ expression.

\section{Integrin Stimulation Results in an Increase in PGC-1 $\alpha$ Expression and $\mathrm{O}_{2}$ Consumption}

These findings suggest that sNAG stimulation results in an activation of Akt1 leading to an increased expression of PGC- $1 \alpha$. Since sNAG treatment is known to bind to and activate integrin-mediated signaling, we tested whether itresulted in an association between ILK1 and Akt1. ILK1 is a downstream kinase of integrin $\beta 1$, bind- 


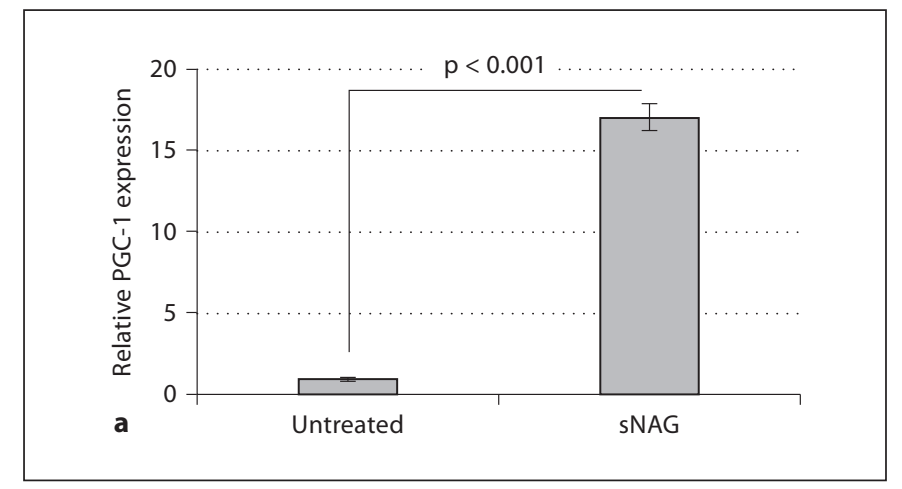

Fig. 3. sNAGs stimulate PGC-1 $\alpha$ expression. a Graph of the confirmation of the gene array analysis using real-time PCR showing the fold induction of untreated and sNAG-treated HUVEC (50 $\mu \mathrm{g} / \mathrm{ml}$ ) for $5 \mathrm{~h}$. b Western blot analysis of total protein isolated from serum-starved HUVEC treated with or without sNAGs (50 $\mu \mathrm{g} / \mathrm{ml}$ ) and probed using an antibody directed against PGC- $1 \alpha$. c Serum-starved HUVEC were either pretreated with PD098059 $(50 \mu \mathrm{M})$ or wortmannin $(100 \mathrm{nM})$ for $30 \mathrm{~min}$ prior to stimulation with sNAGs $(50 \mu \mathrm{g} / \mathrm{ml})$ and assessed for PGC-1 $\alpha$ expression by RT-PCR. The ribosomal protein subunit, S26, was used as a loading control.d Quantitative PCR of the pharmacological inhibitors (as in b). These assays were repeated at least 3 times, each time in triplicate. $\mathrm{C}=\mathrm{sNAG}$-treated control; $\mathrm{PD}=$ pyruvate dehydrogenase; $\mathrm{SS}=$ serum-starved; WTM = wortmannin.

ing to and activating Akt1 in response to integrin engagement [26-28]. To test whether sNAG treatment induces an association between Akt1 and ILK1, Western blot analyses were performed on ILK immunoprecipitations using antibodies directed against Akt1. sNAG treatment induced an association between Akt1 and ILK1 without affecting the expression level of ILK1 (fig. 5a). These findings suggest that Akt1 activation by sNAG treatment is dependent on integrin signaling through ILK1.

As discussed above, sNAG binds tightly to and activates integrins. To determine if the sNAG-dependent stimulation of PGC- $1 \alpha$ expression is also integrin-dependent, blocking antibodies were used to disrupt integrinmediated signaling in endothelial cells. The effect of these antibodies on sNAG-induced PGC-1 $\alpha$ expression was assessed by RT-PCR (fig. 5b) and Western blot analysis (fig. 5 c). Antibody blockade of either $\alpha 5 \beta 1$ (CD49e) or $\beta 1$ integrin resulted in the inhibition of pGlcNAc-induced PGC-1 $\alpha$ expression, whereas treatment with an isotype control antibody did not, indicating the dependence on integrin-mediated signaling in the control of PGC-1 $\alpha$ expression.
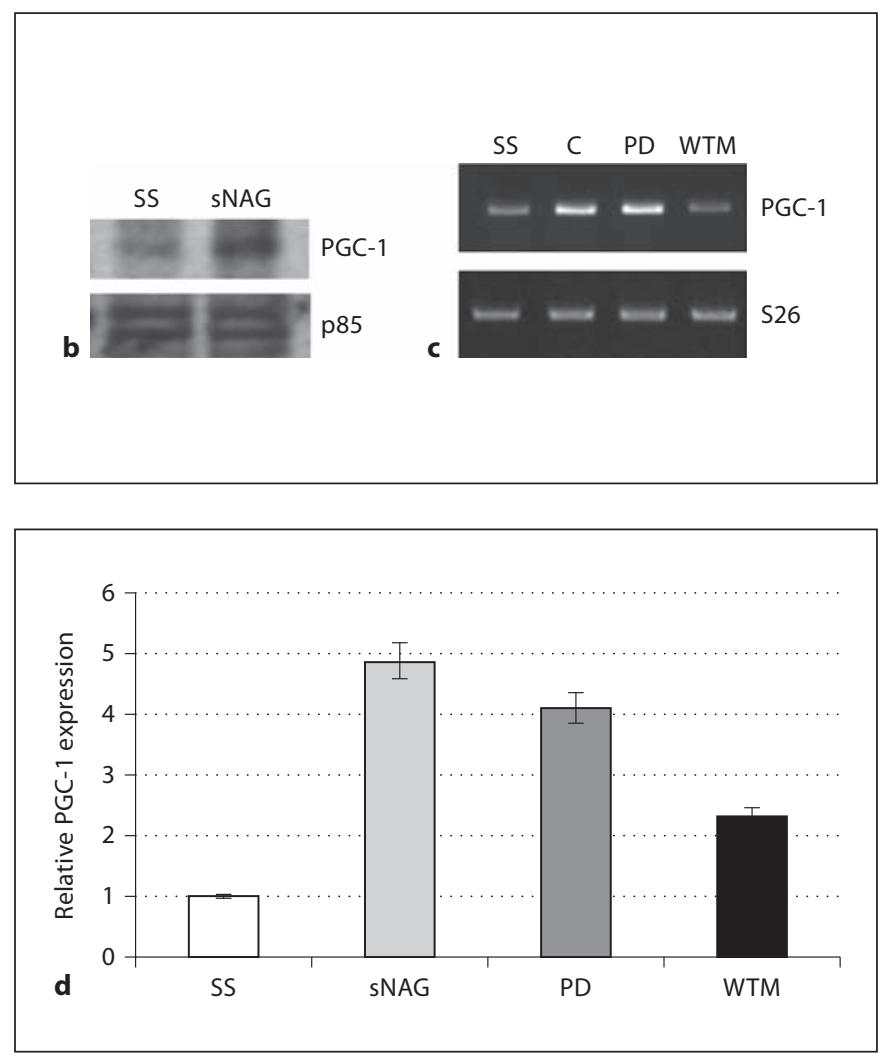

The Integrin-Dependent Akt1/PGC-1 $\alpha$ Pathway

Stimulates Fatty Acid Oxidation

To test whether the upregulation of PGC- $1 \alpha$ correlated with increased mitochondrial biogenesis, changes in mitochondrial DNA content and changes in the expression of the mitochondrial-genome encoded gene, coxII, and the nuclear enome-encoded complex IV-associated protein, coxV1b, were assessed in response to sNAG treatment. The mitochondrial DNA content of the mitochondrial encoded gene coxI, as measured by PCR, remained unchanged in response to nanofiber treatment (fig. 6a). Mitochondrial coxII mRNA expression remained unchanged in response to either nanofiber stimulation or to pharmacological inhibition (fig. 6b). Western blot analysis of complex IV expression also showed no change in response to nanofiber treatment after $3 \mathrm{~h}$ of treatment, although there was a slightly decreased expression after $12 \mathrm{~h}$ (fig. 6c). These findings suggest that integrin activation of PGC- $1 \alpha$ does not stimulate mitochondrial biogenesis.

One downstream effect of PGC- $1 \alpha$ activation is the regulation of the PDK, of which there are 4 isoforms (PDK1-4). PGC-1 $\alpha$ stimulates the expression of PDKs which can inhibit the pyruvate dehydrogenase complex 


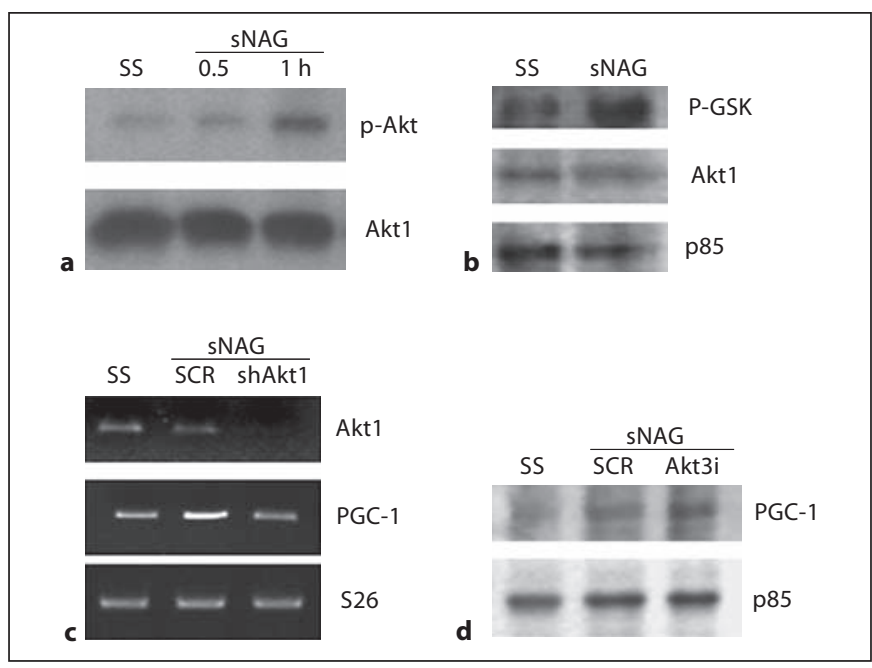

Fig. 4. Akt1 is required for the sNAG-induction of PGC-1 $\alpha$ expression. a Western blot analysis of total protein isolated from serum-starved HUVEC stimulated with sNAGs $(50 \mu \mathrm{g} / \mathrm{ml})$ for the times indicated and assessed for the phosphorylated form of Akt (p-Akt) and total Akt. b Total protein isolated from serumstarved HUVEC stimulated with sNAGs for $1 \mathrm{~h}$, immunoprecipitated with an antibody directed against Akt1 and assessed using a nonradioactive Akt kinase assay. p-GSK, total Akt1 and p85 as a loading control are shown. c Total RNA - isolated from cells either serum-starved or infected with either a scrambled shRNA control or Akt1 shRNA lentiviruses for $48 \mathrm{~h}$ and then stimulated with sNAGs $(50 \mu \mathrm{g} / \mathrm{ml})$ for $6 \mathrm{~h}$ - was assessed by RT-PCR using primers directed against Akt1, PGC-1 $\alpha$ and S26 as a loading control. d Western blot analysis of PGC- $1 \alpha$ isolated from cells either serum-starved or infected with either a scrambled control RNAi or an Akt3 RNAi for $48 \mathrm{~h}$ and then stimulated with sNAGs (50 $\mu \mathrm{g} / \mathrm{ml}$ ) for $6 \mathrm{~h}$; $\mathrm{p} 85$ is shown as a loading control. SCR $=$ Scrambled control; SS = serum-starved.

via phosphorylation, thereby causing a switch from glucose utilization to fatty acid utilization. To test whether sNAG treatment modulates any of the 4 PDK isoforms, serum-starved HUVEC were stimulated with sNAG treatment and assessed for changes in PDK1-4 expression by RT-PCR; PDK4 was markedly upregulated (fig. 6d), 2.5-fold, compared to the serum-starved control. This increased expression was blocked by infection with shRNA directed against Akt1 (fig. 6e), indicating that this Akt1 pathway may control the expression of PDK4. It was also blocked by transfection of an RNAi directed against ILK1, confirming its role in the regulation of PDK4 expression upstream of Akt1. We also detected a slight increase in PDK2 expression (data not shown).

Given the role of PDK4 in the switch between glucose and fatty acid utilization, we tested whether the inhibi-

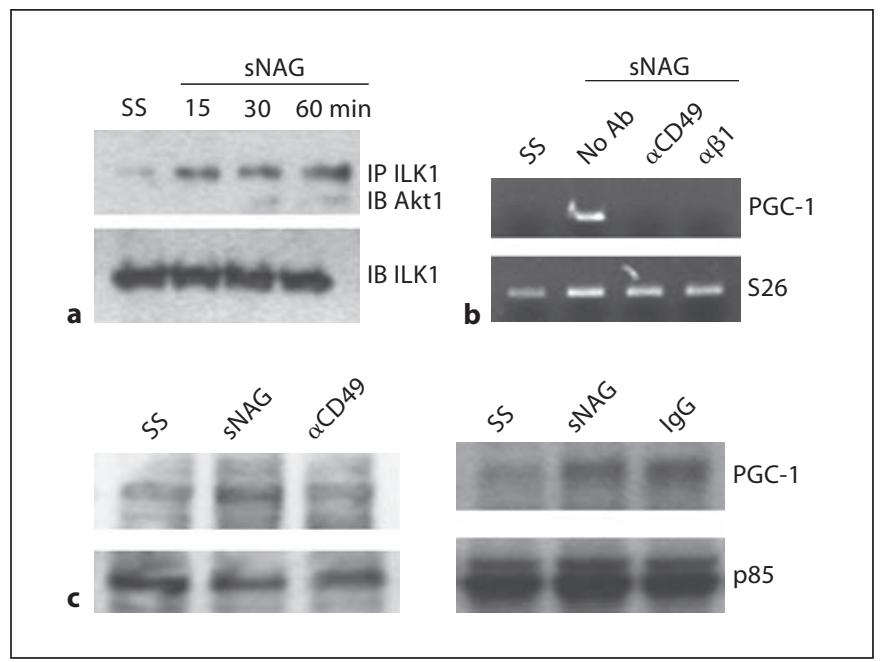

Fig. 5. Integrin stimulation results in increased $\mathrm{O}_{2}$ consumption and PGC- $1 \alpha$ expression. a Total protein from serum-starved HUVEC treated with or without sNAGs for the times indicated was subjected to immunoprecipitation using an antibody directed against ILK1 (IP ILK1) and probed with an antibody directed against Akt1 (IB Akt1). Total ILK1 is also shown. b RT-PCR of total RNA isolated from serum-starved EC pretreated with or without antibodies (No Ab) directed against $\alpha 5 \beta 1$ or $\beta 1$ (CD49) prior to stimulation with sNAGs $(50 \mu \mathrm{g} / \mathrm{ml})$ and performed using primers directed against PGC- $1 \alpha$ or S26 as an internal control. These assays were repeated at least 3 times. c Western blot analysis of PGC- $1 \alpha$ in serum-starved (SS) cells pretreated with $\alpha \mathrm{CD} 49$ blocking antibody followed by treatment with sNAGs $(50 \mu \mathrm{g} / \mathrm{ml})$. Similarly treated cells were also pretreated with an isotype control antibody followed by sNAG treatment.

tion of O-carnitine palmitoyltransferase-1 (CPT-1) with etomoxir would block the increased $\mathrm{O}_{2}$ consumption induced by nanofiber treatment. CPT-1 is associated with the outer mitochondrial membrane and mediates the transport of long-chain fatty acids into the mitochondria. Blockade of CPT-1 with etomoxir, a nonreversible, covalently binding inhibitor, blocks fatty acid transport resulting in a marked inhibition of fatty acid oxidation by the mitochondria. As shown in figure 7a, the inhibition of long-chain fatty acid transport into the mitochondria with etomoxir attenuated the increase in $\mathrm{O}_{2}$ consumption elicited by nanofiber treatment. To confirm that sNAG treatment results in increased fatty acid catabolism, serum-starved or sNAG-treated HUVEC were pulse-labeled with ${ }^{3} \mathrm{H}-9,10$-palmitate. During the acyl-CoA dehydrogenase steps of beta-oxidation, the palmitate ${ }^{3} \mathrm{H}$ atoms are oxidized forming ${ }^{3} \mathrm{H}^{+}$and, thus, the rate of the formation of ${ }^{3} \mathrm{HOH}$ is an estimate of fatty acid oxidation. As shown in figure $7 \mathrm{~b}$, sNAG treatment resulted in an 


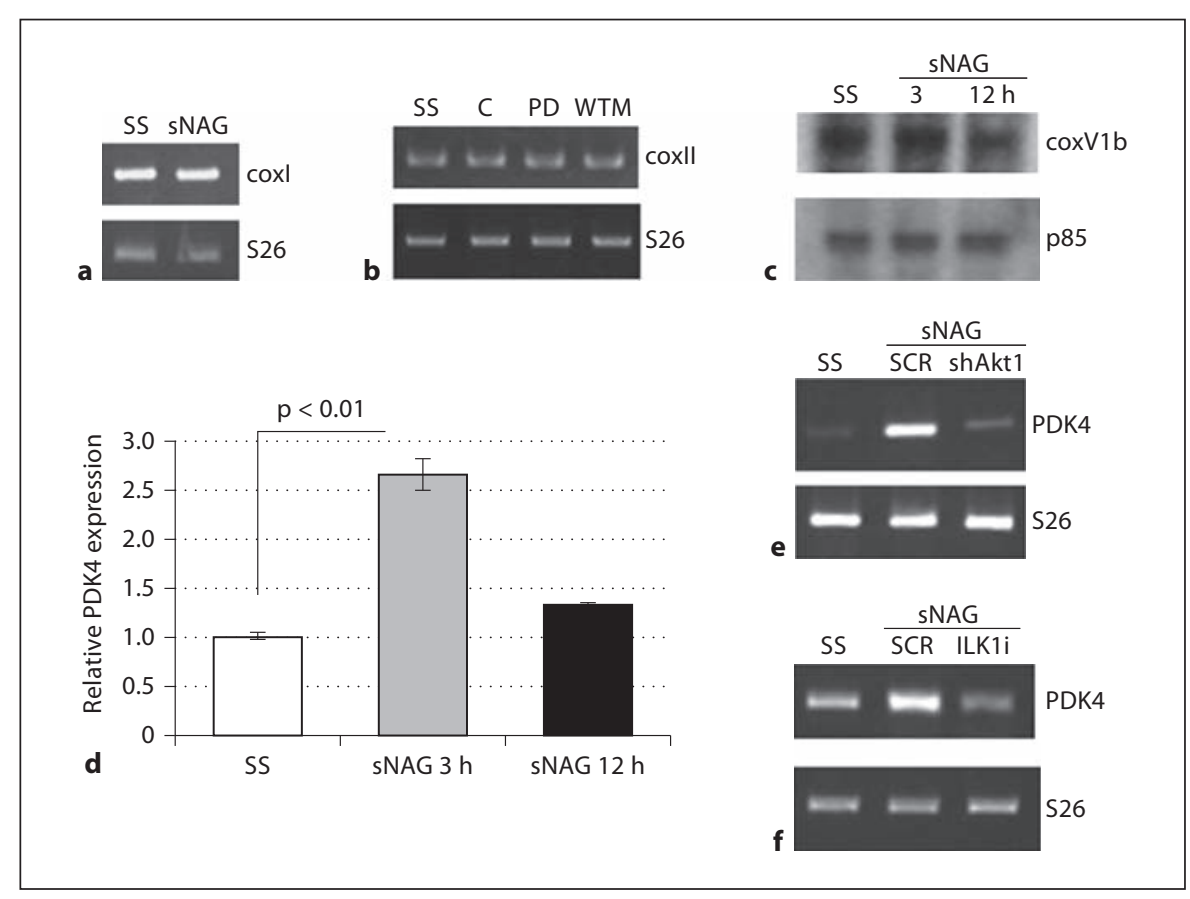

Fig. 6. sNAG stimulation increases PDK4 expression not mitochondrial biogenesis. a Total DNA was isolated from HUVEC either serum-starved or stimulated with sNAGs $(50 \mu \mathrm{g} / \mathrm{ml})$ for $5 \mathrm{~h}$ and subjected to PCR using primers directed against the mitochondrial gene coxI. b Total RNA was isolated from serumstarved HUVEC stimulated with sNAGs $(50 \mu \mathrm{g} / \mathrm{ml})$ with or without pretreatment with PD098059 $(50 \mu \mathrm{M})$ or wortmannin (100 $\mathrm{nM}$ ) for $30 \mathrm{~min}$ and subjected to RT-PCR using primers directed against mitochondrial coxII. c Western blot analysis of coxV1b from total protein isolated from HUVEC serum-starved or stimulated with sNAGs $(50 \mu \mathrm{g} / \mathrm{ml})$ for the times indicated. The PI3K

increased production of ${ }^{3} \mathrm{HOH}$. To confirm that PDK4 is, at least in part, responsible for the increase in palmitate uptake, HUVEC were transfected with an RNAi directed against PDK4 and assessed for palmitate uptake in the presence of sNAGs. As shown in figure 7c, PDK4 knockdown reduces the uptake of palmitate.

The findings presented suggest that integrin stimulation by sNAGs results in an ILK1/Akt1/PDK4 pathway that increases the utilization of fatty acids, thus increasing the energy supply. Our previous studies have shown that the primary effect of sNAG stimulation is an increase in cell motility. To test whether the PDK4 stimulation of fatty acid utilization results in increased cell motility, the effect of PDK4 knockdown was tested using transwell assays. As shown in figure 7d, sNAG stimulation of HUVEC results in a 5 -fold increase in cell migration and the blockade of PDK4 expression blunts this response. p85 subunit is shown as a loading control. $\mathbf{d}$ Quantitative PCR of cells treated (as in c) and assessed for PDK4 expression and expressed as relative to the internal control. e Total RNA isolated from HUVEC infected with either a scrambled control or Akt1 shRNA lentivirus followed by sNAG treatment assessed for PDK4 expression by RT-PCR. $\mathbf{f}$ Total RNA isolated from HUVEC transfected with either a scrambled control or ILK1 RNAi followed by sNAG treatment and assessed for PDK4 expression by RT-PCR. $\mathrm{C}=$ sNAG-treated control; $\mathrm{SCR}=$ scrambled control; $\mathrm{SS}=$ serumstarved; WTM = wortmannin.

Taken together, our findings suggest a model (fig. 8) whereby sNAG stimulation of outside-in integrin signaling results in the ILK1 activation of Akt1. Increased Akt1 activation results in an upregulation of PGC-1 $\alpha$ which controls the expression of PDK4. PDK4 is known to negatively regulate pyruvate dehydrogenase resulting in a switch from glucose utilization to fatty acid oxidation. Increased fatty acid oxidation would therefore compensate for the increased energy demand for such processes as cellular movement.

\section{Discussion}

We have previously found that, in the absence of any exogenous growth factors, sNAG treatment induces endothelial cell motility and in vitro angiogenesis. This effect is mediated by an induction of an integrin-depen- 


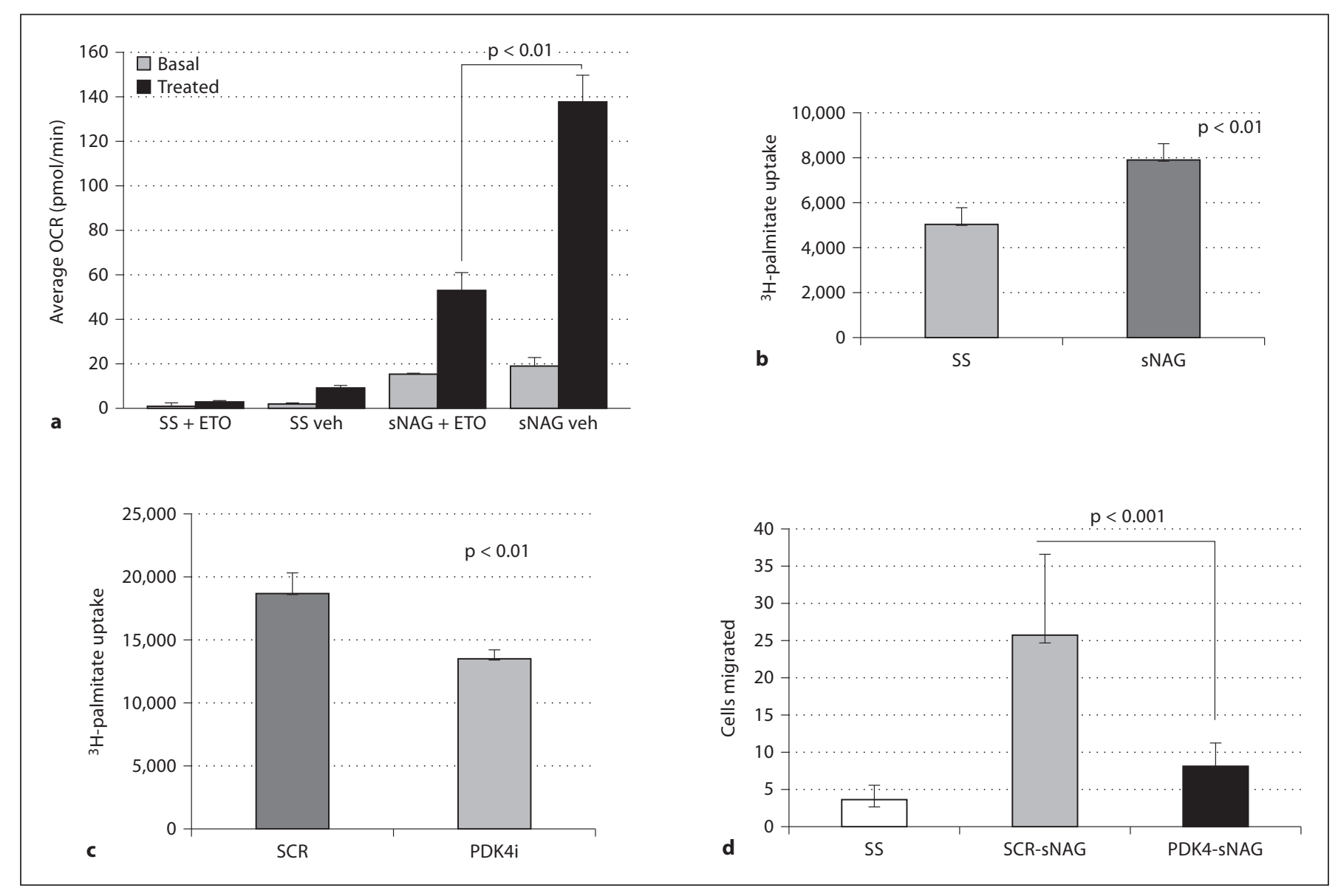

Fig. 7. sNAGs stimulate $\mathrm{O}_{2}$ consumption rates via fatty acid oxidation. a Serum-starved HUVEC were treated with or without sNAGs $(50 \mu \mathrm{g} / \mathrm{ml})$ overnight. The basal rates were measured and then etomoxir or vehicle control was injected. The $\mathrm{O}_{2}$ consumption rates (OCR) of sNAG-treated and serum-starved HUVEC (with/without etomoxir or vehicle) were measured 30 min after injection. $\mathbf{b}^{3} \mathrm{H}$-palmitate uptake experiment showing the cpm of ${ }^{3} \mathrm{H}-\mathrm{H}_{2} \mathrm{O}$ resulting from the overnight stimulation of HUVEC with sNAGs $(50 \mu \mathrm{g} / \mathrm{ml})$. Total $\mathrm{cpm}$ is shown after $1 \mathrm{~h}$ of palmitate uptake. ${ }^{3} \mathrm{H}$-palmitate uptake experiment (as in $\mathbf{b}$ ) using HUVEC stimulated with sNAGs and transfected with either scrambled control or an RNAi directed against PDK4. d Quantitation of the number of cells migrated through transwells coated with fibronectin after transfection with either scrambled control RNAi or PDK4 RNAi and treated with or without sNAGs under serum-starved conditions. $\mathrm{ETO}=$ Etomoxir; SCR = scrambled control; SS = serum-starved; veh = vehicle. dent pathway [14]. We showed here that sNAG stimulation of HUVEC results in a marked increase in respiration in the absence of increased cell numbers. Gene array analyses have defined a potential regulation of PGC- $1 \alpha$ expression in response to sNAG stimulation. We found that Akt1 exerts a positive control on the expression of PGC- $1 \alpha$ and that the increased expression of PGC- $1 \alpha$ results in an increased expression of PDK4. PDK4 is a known downstream target of PGC- $1 \alpha$ and a potent regulator of the pyruvate dehydrogenase complex that controls the utilization of glucose and fatty acids $[29,30]$. These findings suggest that the increased $\mathrm{O}_{2}$ consumption elicited by nanofiber treatment may be due to increased fatty acid oxidation. To test this hypothesis, an O-carnitine palmitoyltransferase-1 inhibitor (etomoxir) was used. We found that the sNAG-dependent increase in $\mathrm{O}_{2}$ consumption arises from increased expression of PDK4 and a subsequent switch to fatty acid oxidation. Our findings suggest that increased oxygen consumption by sNAG-treated primary endothelial cells is due to the activation of an integrin/Akt1/ PGC1 $\alpha$ pathway that modulates the expression of PDK4, leading to a switch from glucose utilization to fatty acid oxidation. 


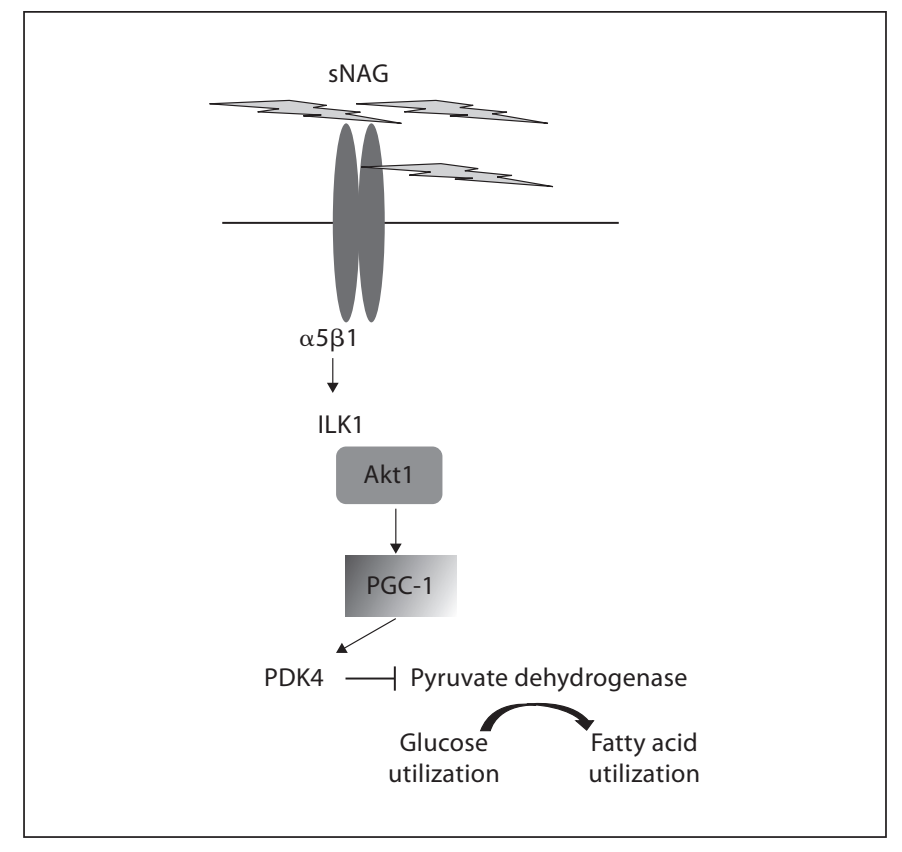

Fig. 8. Model of the signaling pathway stimulated by sNAGs, that results in an integrin-dependent increase in fatty acid oxidation. sNAGs stimulate outside-in signaling of integrins resulting in an activation of Akt1 via the association of ILK1. Akt1 activation leads to an increase in the expression of PGC-1 $\alpha$ which controls the expression of PDK4. PDK4 functions to inhibit the activity of pyruvate dehydrogenase, thus promoting the switch from glucose to fatty acid metabolism.

Glucose is typically the major bioenergetic substrate for tissues in which it is used to derive ATP via glycolysis and the subsequent mitochondrial oxidation of pyruvate, and to derive ribose and NADH via the pentose phosphate pathway. Tissue with a high metabolic demand and sufficient $\mathrm{O}_{2}$ will often show a preference for the utilization of free fatty acids because these have about twice the energy density of carbohydrates. However, fatty acid oxidation requires more $\mathrm{O}_{2}$ per ATP produced than does glucose utilization via pyruvate oxidation. Thus, even with no increase in ATP turnover, a simple switch from predominately glucose to predominately fatty acid utilization will lead to an increase in respiration, as seen in sNAGactivated HUVEC. Highly anabolic processes such as the formation of new vasculature is inherently energy consuming. The findings presented here suggest that one activity of activated Akt1 is to increase cellular energetics, at least partly, through increased fatty acid utilization.

A highly pure and homogenous formulation of sNAGs isolated from a marine diatom is the active ingredient in several FDA-cleared products used clinically as hemo- static agents $[8,9,31]$, which cause the activation of platelets and red blood cells leading to the formation of a fibrin clot [32]. Importantly, platelet activation by sNAGs is mediated by their association with integrin $\beta 3$ and activation of integrin-mediated signaling [11]. sNAGs have also been shown to be efficacious in the treatment of wounds [13], resulting in the stimulation of integrin-mediated cell motility, increased in vitro angiogenesis and wound closure [14]. The effects of nanofiber treatment can be explained, at least in part, by an integrin-dependent regulation of cellular signaling, suggesting its use as a tool to dissect the molecular mechanisms regarding cell-cell and cell-matrix interactions. We show that the induction of PGC- $1 \alpha$ expression in HUVEC is dependent on the sNAG stimulation of integrin and that this results in increased respiration. These findings support the idea that sNAGs activate integrin-mediated signaling; although this does not rule out the possibility of other levels of regulation. The exact mechanism by which sNAGs stimulate integrin has yet to be determined.

We have previously shown that Akt1 is a regulator of Ets1 expression in primary HUVEC and that this pathway is required for angiogenesis and branching morphogenesis in vivo [33]. Here we show that sNAG stimulation leads to the activation of Akt1 and that blockade of Akt1 by shRNA results in a reduction in the nanofiber-dependent stimulation of PGC- $1 \alpha$ expression. Others have shown that PGC- $1 \alpha$ transcription is regulated by CREB and the forkhead in rhabdomyosarcoma transcription factor [34], both downstream effectors of Akt1 [35,36]. Whether the Akt1/Ets1 pathway is also involved in the transcriptional regulation of PGC-1 $\alpha$ remains to be determined.

Aktl activation plays a central role in the control of integrin signaling in HUVEC, acting both upstream of integrin $\beta 3$ in the regulation of cell motility and actin dynamics $[37,38]$ and downstream of integrin outside-in signal transduction via the activation of ILK [27]. In vivo, the absence of Akt1 results in impaired integrin activation in both endothelial cells and fibroblasts [39]. Our results suggest that the activation of integrin by sNAGs results in increased Akt1 activation via ILK1 and that this interaction leads to the regulation of PGC- $1 \alpha$ and $\mathrm{O}_{2}$ consumption in a pathway independent of other Akt family members. Given the potential energy requirements for integrin-dependent cellular processes such as cell motility, it is possible that integrin activation would result in increased metabolic capacity. Others have also shown that integrin-mediated signaling can affect mitochondrial function, such as increased reactive oxygen production. Such changes in mitochondrial function have been 
thought to be a prerequisite for further downstream events such as NFKB activation and shape change. These processes are thought to be Rac1-dependent [40, 41]. Given a role for Akt1 in integrin/Racl signaling [42-44], these pathways may be interconnected.

The Akt family of kinases is comprised of three highly homologous members; Akt1, 2 and 3 [45, 46]. Overexpression of constitutively activated forms of individual family members results in similar phenotypes in epithelial cells and in lymphoid cells [47]. Although this family of kinases is considered in part functionally redundant [48], these three kinases have distinct functions in specific cell types [49-51]. Our findings suggest that different Akt family members act upon PGC-1 $\alpha$ in both cellcontext and signal-dependent manners. We have shown, in primary endothelial cells, that Akt 3 regulates PGC-1 $\alpha$ nuclear/cytoplasmic transport and that the blockade of Akt3 results in a reduction in PGC-1 $\alpha$-dependent mitochondrial biogenesis [25]. Others have shown that, in the liver, direct phosphorylation of PGC- $1 \alpha$ by Akt 2 prevents recruitment of this coactivator to its associated promoters resulting in a downregulation of PGC- $1 \alpha$ transcriptional activity. Akt3 as a downstream effector of VEGF in HUVEC results in PGC-1 $\alpha$ nuclear accumulation and activation of its downstream targets (NRF-1, MCAD) [25]. Akt2 in the liver directly phosphorylates and inhibits PGC-1 $\alpha$ in response to insulin-mediated signaling [52]. Here we show that integrin stimulation activates Akt1 and leads to an upregulation of PGC-1 $\alpha$ expression and its downstream target, PDK4, in HUVEC. In primary endothelial cells then, two of the major functions of PGC-
$1 \alpha$ are differentially controlled by Akt 1 and Akt3, Akt3 leading to mitochondrial biogenesis and Akt1 leading to fatty acid oxidation. Activation of either kinase in this cellular context results in increased PGC- $1 \alpha$ activity either by increased expression (Akt1) or by increased nuclear accumulation (Akt3) [25], each resulting in markedly different downstream effects. Given that we do not detect Akt2 expression in HUVEC, it still has to be determined whether insulin activation of Akt1 (or Akt3) compensates for Akt2 activity in this cell type. However, the effects of Akt3 on mitochondrial biogenesis are not compensated by Akt1. The blockade of Akt1 has little effect on mitochondrial biogenesis, only the blockade of Akt3 results in this phenotype [25].

A hallmark of gene families is the ability for one member to compensate for another family member. However, conservation of different family members suggests independent function. This is the case with the Akt family and explains the mild phenotypes of the single knockout animals. However, as discussed, each Akt family member retains individual and specific functions. A full understanding of the mechanisms elicited by each Akt family member in the regulation of PGC-1 $\alpha$ function has yet to be elucidated.

\section{Acknowledgements}

This work was supported by grants R01 HL84565 (R.C.M.-H.) and Marine Polymer Technologies (R.C.M.-H. and A.S.). We thank Sunnybrook Genomic Core Facility for assistance with the microarray analysis.

\section{References}

1 Singer AJ, Clark RA: Cutaneous wound healing. N Engl J Med 1999;341:738-746.

-2 Galiano RD, Tepper OM, Pelo CR, Bhatt KA, Callaghan M, Bastidas N, Bunting S, Steinmetz HG, Gurtner GC: Topical vascular endothelial growth factor accelerates diabetic wound healing through increased angiogenesis and by mobilizing and recruiting bone marrow-derived cells. Am J Pathol 2004;164: 1935-1947.

- 3 Hong YK, Lange-Asschenfeldt B, Velasco P, Hirakawa S, Kunstfeld R, Brown LF, Bohlen P, Senger DR, Detmar M: VEGF-A promotes tissue repair-associated lymphatic vessel formation via VEGFR-2 and the alphalbeta1 and alpha2beta1 integrins. FASEB J 2004; 18 : 1111-1113.

-4 Tonnesen MG, Feng X, Clark RA: Angiogenesis in wound healing. J Investig Dermatol Symp Proc 2000;5:40-46.
5 Madeddu P: Therapeutic angiogenesis and vasculogenesis for tissue regeneration. Exp Physiol 2005;90:315-326.

-6 Yla-Herttuala S, Markkanen JE, Rissanen TT: Gene therapy for ischemic cardiovascular diseases: some lessons learned from the first clinical trials. Trends Cardiovasc Med 2004; 14:295-300.

7 Katsube K, Bishop AT, Simari RD, Yla-Herttuala S, Friedrich PF: Vascular endothelial growth factor (VEGF) gene transfer enhances surgical revascularization of necrotic bone. J Orthop Res 2005;23:469-474.

8 Hirsch JA, Reddy SA, Capasso WE, Linfante I: Non-invasive hemostatic closure devices: 'Patches and pads'. Tech Vasc Interv Radiol 2003;6:92-95.

9 Palmer BL, Gantt DS, Lawrence ME, Rajab $\mathrm{MH}$, Dehmer GJ: Effectiveness and safety of manual hemostasis facilitated by the syvek- patch with one hour of bedrest after coronary angiography using six-french catheters. Am J Cardiol 2004;93:96-97.

10 Thatte HS, Zagarins S, Khuri SF, Fischer TH: Mechanisms of poly- $\mathrm{N}$-acetyl glucosamine polymer-mediated hemostasis: platelet interactions. J Trauma 2004;57:S13-S21.

11 Fischer TH, Thatte HS, Nichols TC, BenderNeal DE, Bellinger AD, Vournakis JN: Synergistic platelet integrin signaling and factor xii activation in poly- $\mathrm{N}$-acetyl glucosamine fiber-mediated hemostasis. Biomaterials 2005;26:5433-5443.

12 Pietramaggiori G, Yang HJ, Scherer SS, Kaipainen A, Chan RK, Alperovich M, Newalder J, Demcheva M, Vournakis JN, Valeri CR, Hechtman HB, Orgill DP: Effects of poly-Nacetyl glucosamine (PGLCNAC) patch on wound healing in $\mathrm{db} / \mathrm{db}$ mouse. J Trauma 2008;64:803-808. 
13 Scherer SS, Pietramaggiori G, Matthews J, Perry S, Assmann A, Carothers A, Demcheva M, Muise-Helmericks RC, Seth A, Vournakis JN, Valeri RC, Fischer TH, Hechtman HB, Orgill DP: Poly-N-acetyl glucosamine nanofibers: a new bioactive material to enhance diabetic wound healing by cell migration and angiogenesis. Ann Surg 2009;250:322-330.

14 Vournakis JN, Eldridge J, Demcheva M, Muise-Helmericks RC: Poly-N-acetyl glucosamine nanofibers regulate endothelial cell movement and angiogenesis: dependency on integrin activation of Ets1. J Vasc Res 2008;45:222-232.

15 Lin J, Handschin C, Spiegelman BM: Metabolic control through the PGC-1 family of transcription coactivators. Cell Metab 2005; 1:361-370.

- 16 Mootha VK, Lindgren CM, Eriksson KF, Subramanian A, Sihag S, Lehar J, Puigserver P, Carlsson E, Ridderstrale M, Laurila E, Houstis N, Daly MJ, Patterson N, Mesirov JP, Golub TR, Tamayo P, Spiegelman B, Lander ES, Hirschhorn JN, Altshuler D, Groop LC: PGC-1alpha-responsive genes involved in oxidative phosphorylation are coordinately downregulated in human diabetes. Nat Genet 2003;34:267-273.

17 Puigserver P, Spiegelman BM: Peroxisome proliferator-activated receptor-gamma coactivator 1 alpha (PGC-1 alpha): transcriptional coactivator and metabolic regulator. Endocr Rev 2003;24:78-90.

-18 Lehman JJ, Barger PM, Kovacs A, Saffitz JE, Medeiros DM, Kelly DP: Peroxisome proliferator-activated receptor gamma coactivator-1 promotes cardiac mitochondrial biogenesis. J Clin Invest 2000;106:847-856.

-19 Lin J, Wu H, Tarr PT, Zhang CY, Wu Z, Boss O, Michael LF, Puigserver P, Isotani E, Olson EN, Lowell BB, Bassel-Duby R, Spiegelman BM: Transcriptional co-activator PGC-1 alpha drives the formation of slow-twitch muscle fibres. Nature 2002;418:797-801.

20 Kelly DP, Scarpulla RC: Transcriptional regulatory circuits controlling mitochondrial biogenesis and function. Genes Dev 2004; 18 : 357-368.

21 Ojuka EO: Role of calcium and AMP kinase in the regulation of mitochondrial biogenesis and glut 4 levels in muscle. Proc Nutr Soc 2004:63:275-278.

22 Wu H, Kanatous SB, Thurmond FA, Gallardo T, Isotani E, Bassel-Duby R, Williams RS: Regulation of mitochondrial biogenesis in skeletal muscle by CAMK. Science 2002;296: 349-352.

23 Barger PM, Browning AC, Garner AN, Kelly DP: P38 mitogen-activated protein kinase activates peroxisome proliferator-activated receptor alpha: a potential role in the cardiac metabolic stress response. J Biol Chem 2001; 276:44495-44501.

24 Nemoto S, Fergusson MM, Finkel T: SIRT1 functionally interacts with the metabolic regulator and transcriptional coactivator PGC1 \{alpha\}. J Biol Chem 2005;280:16456-16460.
25 Wright GL, Maroulakou IG, Eldridge J, Liby TL, Sridharan V, Tsichlis PN, Muise-Helmericks RC: VEGF stimulation of mitochondrial biogenesis: requirement of Akt3 kinase. FASEB J 2008.

26 Delcommenne M, Tan C, Gray V, Rue L, Woodgett J, Dedhar S: Phosphoinositide-3$\mathrm{OH}$ kinase-dependent regulation of glycogen synthase kinase 3 and protein kinase B/ Akt by the integrin-linked kinase. Proc Natl Acad Sci USA 1998;95:11211-11216.

27 Nho RS, Xia H, Kahm J, Kleidon J, Diebold D, Henke CA: Role of integrin-linked kinase in regulating phosphorylation of Akt and fibroblast survival in type I collagen matrices through a betal integrin viability signaling pathway. J Biol Chem 2005;280:26630-26639.

28 Persad S, Attwell S, Gray V, Delcommenne M, Troussard A, Sanghera J, Dedhar S: Inhibition of integrin-linked kinase (ILK) suppresses activation of protein kinase B/Akt and induces cell cycle arrest and apoptosis of PTEN-mutant prostate cancer cells. Proc Natl Acad Sci USA 2000;97:3207-3212.

29 Zhang Y, Ma K, Sadana P, Chowdhury F, Gaillard S, Wang F, McDonnell DP, Unterman TG, Elam MB, Park EA: Estrogen-related receptors stimulate pyruvate dehydrogenase kinase isoform 4 gene expression. J Biol Chem 2006;281:39897-39906.

30 Connaughton S, Chowdhury F, Attia RR, Song S, Zhang Y, Elam MB, Cook GA, Park EA: Regulation of pyruvate dehydrogenase kinase isoform 4 (PDK4) gene expression by glucocorticoids and insulin. Mol Cell Endocrinol 2010;315:159-167.

-31 King DR, Cohn SM, Proctor KG: Modified rapid deployment hemostat bandage terminates bleeding in coagulopathic patients with severe visceral injuries. J Trauma 2004; 57:756-759.

32 Fischer TH, Valeri CR, Smith CJ, Scull CM, Merricks EP, Nichols TC, Demcheva M, Vournakis JN: Non-classical processes in surface hemostasis: mechanisms for the poly-N-acetyl glucosamine-induced alteration of red blood cell morphology and surface prothrombogenicity. Biomed Mater 2008;3:15009.

33 Lavenburg KR, Ivey J, Hsu T, Muise-Helmericks RC: Coordinated functions of Akt/PKB and Ets1 in tubule formation. FASEB J 2003; 17:2278-2280.

34 Daitoku H, Yamagata K, Matsuzaki H, Hatta M, Fukamizu A: Regulation of PGC-1 promoter activity by protein kinase $\mathrm{B}$ and the forkhead transcription factor FKHR. Diabetes 2003;52:642-649.

35 Woods A, Couchman JR: Syndecans: synergistic activators of cell adhesion. Trends Cell Biol 1998;8:189-192.

$36 \mathrm{Du} \mathrm{K}$, Montminy M: CREB is a regulatory target for the protein kinase Akt/PKB. J Biol Chem 1998;273:32377-32379.

-37 Somanath PR, Kandel ES, Hay N, Byzova TV: Akt1 signaling regulates integrin activation, matrix recognition, and fibronectin assembly. J Biol Chem 2007;282:22964-22976.
38 Mahabeleshwar GH, Byzova TV: Vascular integrin signaling. Methods Enzymol 2008; 443:199-226.

39 Somanath PR, Chen J, Byzova TV: Aktl is necessary for the vascular maturation and angiogenesis during cutaneous wound healing. Angiogenesis 2008;11:277-288.

40 Werner E, Werb Z: Integrins engage mitochondrial function for signal transduction by a mechanism dependent on Rho GTPases. J Cell Biol 2002;158:357-368.

41 Radisky DC, Levy DD, Littlepage LE, Liu H, Nelson CM, Fata JE, Leake D, Godden EL, Albertson DG, Nieto MA, Werb Z, Bissell MJ: Raclb and reactive oxygen species mediate MMP-3-induced EMT and genomic instability. Nature 2005;436:123-127.

42 Zhou GL, Tucker DF, Bae SS, Bhatheja K, Birnbaum MJ, Field J: Opposing roles for Akt1 and Akt2 in Rac/Pak signaling and cell migration. J Biol Chem 2006;281:36443-36453.

43 Welch H, Eguinoa A, Stephens LR, Hawkins PT: Protein kinase $B$ and Rac are activated in parallel within a phosphatidylinositide $3 \mathrm{oh}$ kinase-controlled signaling pathway. J Biol Chem 1998;273:11248-11256.

44 Kim EK, Tucker DF, Yun SJ, Do KH, Kim MS, Kim JH, Kim CD, Birnbaum MJ, Bae SS: Linker region of Akt1/protein kinase Balpha mediates platelet-derived growth factor-induced translocation and cell migration. Cell Signal 2008;20:2030-2037.

45 Coffer PJ, Jin J, Woodgett JR: Protein kinase B (C-Akt): a multifunctional mediator of phosphatidylinositol 3-kinase activation. Biochem J 1998;335:1-13.

46 Chan TO, Rittenhouse SE, Tsichlis PN: Akt/ $\mathrm{PKB}$ and other $\mathrm{d} 3$ phosphoinositide-regulated kinases: kinase activation by phosphoinositide-dependent phosphorylation. Annu Rev Biochem 1999;68:965-1014.

47 Mende I, Malstrom S, Tsichlis PN, Vogt PK, Aoki M: Oncogenic transformation induced by membrane-targeted Akt2 and Akt3. Oncogene 2001;20:4419-4423.

48 Peng XD, Xu PZ, Chen ML, Hahn-Windgassen A, Skeen J, Jacobs J, Sundararajan D, Chen WS, Crawford SE, Coleman KG, Hay $\mathrm{N}$ : Dwarfism, impaired skin development, skeletal muscle atrophy, delayed bone development, and impeded adipogenesis in mice lacking Akt1 and Akt2. Genes Dev 2003;17: 1352-1365.

49 Chin YR, Toker A: Akt isoform-specific signaling in breast cancer: uncovering an antimigratory role for palladin. Cell Adh Migrat 2011;5:211-214

50 Hay N: Akt isoforms and glucose homeostasis - the leptin connection. Trends Endocrinol Metab 2011;22:66-73.

51 Gonzalez E, McGraw TE: The Akt kinases: isoform specificity in metabolism and cancer. Cell Cycle 2009;8:2502-2508.

52 Li X, Monks B, Ge Q, Birnbaum MJ: Akt/ $\mathrm{PKB}$ regulates hepatic metabolism by directly inhibiting PGC-1alpha transcription coactivator. Nature 2007;447:1012-1016. 